\title{
PANORAMA GERAL DAS ARTES CÊNICAS \\ em Belo Horizonte durante os anos de 1994 a 1999
}

\author{
Marcos Antônio Alexandre \\ UFMG
}

\begin{abstract}
RESUMO
O propósito desse artigo é realizar um panorama das artes cênicas em Belo Horizonte, nos últimos cinco anos, partindo da análise de mais de oitenta espetáculos assistidos nesse período e buscando tecer algumas considerações teó. ricas sobre o direcionamento do teatro em nossa cidade.
\end{abstract}

\section{PALAVRAS - CHAVE}

encenação, Belo Horizonte, grupos teatrais

Nos últimos anos, as artes cênicas em Belo Horizonte cresceram muito em qualidade e diversidade, conseqüência da formação de novos grupos. A dança e o teatro, hoje, em nossa cidade, nāo se resumem mais aos trabalhos dos grupos Corpo, Primeiro Ato e Galpão ( já reconhecidos em todo o país e exterior por suas trajetórias artísticas) ou de outros que vêm do eixo Rio - São Paulo. Atualmente, há uma variedade de atores e bailarinos se integrando a novas montagens e mostrando o seu trabalho na cidade, e essas montagens não se resumem mais a apenas trabalhos comerciais que exploram o humor e a libido. Existem trabalhos mais elaborados, que utilizam performances distintas nas quais linguagens diversificadas são colocadas em cena, através do uso de cenários criativos e alternativos, ou seja, a obra teatral já não se limita mais aos palcos dos grandes teatros. O espetáculo teatral finalmente está sendo ence. nado em espaços como a rua e praças - Dimonis, do grupo Espanhol Comediants (julho de 96), Bivouac (criação coletiva -- Générik Vapeur, França, agosto de 97), Gens de couleurs (criação coletiva do grupo Ilopie, França, julho de 96) e Popon el brujo y el sueño de Tisquesusa, de Fernando Gonzalez Cajiao (Teatro Taller de Colombia); parques - Esperando Godot, de Samuel Beckett, representada pelo grupo Armatrux no Parque das Mangabeiras (julho de 96) e Primeiras estórias, de João Guimarães Rosa, representada pelo Teatro do Bão, de Campinas, sob direção de João das Neves, na Lagoa do Nado; restaurantes populares, ônibus e metrô - Filomena, Zulurdes e Custódia, interpretada pela atriz Gorete Milagres (julho de 96) e Bivouac; porões - Circo bizarro, de Fernando Arrabal, encenado pelos alunos formandos da Escola Profissionalizante da Fundação Clóvis Salgado (janeiro de 96); galpões Divinas palauras, sob direção de Fernando Mencarelli e atuação dos alunos/formandos do Teatro Universitário (dezembro de 96); e museus - Troços e destroços, de João Silvério Trevisan, adaptação e direção de João das Neves, com a atuação dos formandos de 1997 do Curso de Formação de atores do Teatro Universitário. Um dos fatores 
importantes para a efetivação dessa abertura foi a realização dos Festivais Internacionais de Teatro (FIT) e Dança (FID) em nossa cidade.

Grupos de outros estados e países se juntam aos grupos locais e mostram as distintas facetas das artes cênicas. Outro fator, também fundamental, é a campanha de popularização do teatro, que a cada ano leva mais público "comum" aos teatros. Um dos aspectos positivos dessa abertura das artes cênicas é que o ator se aproxima mais do público, quebrando a barreira palco x espectador. As obras, ao saírem dos palcos tradicionais, dão aos espectadores das classes menos favorecidas a oportunidade de terem contato com o universo dramático de distintos autores contemporâneos ou clássicos, como acontece com os trabalhos do grupo Galpão e da Cia de Artes Reviu a Volta, entre outros.

Dentre os trabalhos assistidos nesses últimos cinco anos, podemos destacar:

- de Nelson Rodrigues

1. O beijo no asfalto (encenada pelo grupo Encena, direção de Wilson Oliveira e pela Cia de Artes Reviu a Volta, direção de Marcelo Bones) - obra classificada como tragédia carioca. Arandir, o protagonista da história, presencia um atropelamento na Praça da Bandeira e corre para socorrer a vítima. O atropelado, antes de vir a falecer, pede-lhe um beijo na boca. $O$ que nos parece um ato de simplicidade "um simples beijo" - torna-se o fio condutor da trama trágica da peça.

2. O casamento (grupo Os Fodidos Privilegiados, direção de Antônio Abujamra) - romance de Nelson Rodrigues adaptado para o teatro, que traz como tema central a desestruturalização dos relacionamentos humanos com toda a crueza de linguagem rodriguiana.

- de Gabriel García Márquez: El coronel no tiene quien le escriba (encenada pelo grupo Rajatabla, Venezuela) - texto que nos permite pesquisar um setor marginalizado da sociedade latino-americana. O romance e a peça abordam a problemática dos idosos que vivem em sociedades que não os contemplam.

- Rua da Amargura (trabalho do grupo Galpão, baseado no texto de Eduardo Garrido) - retrata a vida de Jesus Cristo, de seu nascimento à sua morte, colocando em evidência os costumes e as tradições da sociedade mineira, fazendo uso, ao mesmo tempo, da incorporação de elementos circenses e religiosos, próprios de Minas Gerais, à montagem.

- do dramaturgo chileno Marco Antonio de la Parra: El continente negro (texto adaptado e encenado pelo grupo Mayombe, da Faculdade de Letras, UFMG) - obra que pode ser vista como uma "colagem" de várias outras. O texto é apresentado de forma fragmentada, dando a impressão de que a obra trata de histórias completamente independentes. Entretanto, essas tramas, aparentemente independentes, são interligadas por um macro-signo que aparece ao longo de todo o texto e do espetáculo: o sentimento de insegurança das personagens que buscam no continente africano uma saída para superar os problemas.

Através dessa breve exposição de montagens, queremos enfatizar que as obras, na sua grande maioria, têm como referência o texto dramático; há outras, entretanto, que surgem a partir de textos romanescos. Por isso, faz-se necessário que teçamos algumas consideraçōes sobre o texto dramático e o espetacular, bem como o romanesco e sua adaptação na formação do texto espetacular. $O$ que podemos afirmar é que, na grande maioria das montagens originadas de um texto dramático, houve um cui- 
dado por parte da direção em manter-se fiel a esse texto; dentre essas podemos citar a montagem d'O beijo no asfalto, de Nelson Rodrigues. Mesmo quando houve uma adaptação maior ou atualização do texto, o seu macro-signo se manteve. Em algumas montagens, um dos recursos mais utilizados pela direçāo para adaptar o texto dramático foi a exclusão de personagens periféricas, sendo que, às vezes, em alguns trabalhos, outras personagens assumiam as falas das que foram cortadas e em outros simplesmente se ignorou essa ausência. As rubricas do autor presentes no texto são importantes, porque é a partir delas que o diretor vai compor as cenas, porém elas, em si, ao se associarem às palavras, não bastam para "dar vida" ao texto dramático, transformando-o em espetacular. As distintas linguagens que compõem o texto espetacular (luz, cenário, figurino, sonoplastia, etc.), aliadas à figura do ator em cena, se transformam nos recursos que o diretor utiliza para conceber e realizar a sua visão espetacular do texto. Nesse contexto, o ator assume, quase sempre, uma funçāo indispensável na composição da montagem, visto que ele utiliza as palavras e as palavras, no texto, não representam ação espetacular. A "dramaturgia do ator", ${ }^{1}$ através da composição de ações físicas e vocais (gestos, movimentos físicos, verbais e vocais), corporiza essas palavras. Nesse caso, os gestos acompanham a palavra, mas não deve ser sempre assim. Há que buscar, através dos movimentos cênicos, a justificação interior da personagem e para isso é necessária a presença total do ator, que nāo pode deixar que seu trabalho se apoie na gestualidade exterior (vazia, composta apenas de movimentos decorativos, sem conteúdo). $O$ ator pode inclusive produzir ações simples no palco desde que sejam justificadas pelos movimentos interiores. No comportamento cênico há necessidade de plasticidade, uma energia que sai do centro do corpo e é transmitida a todo corpo e essa energia só é despertada através das açōes conscientes. Daí, a importância do texto dramático na composição do trabalho atoral. É fundamental o que está nas entrelinhas das palavras do autor. Essas palavras pertencem a ele, mas o diretor e o ator criam sub-textos. Stanislavski enfatiza que o ator é o romancista da personagem. ${ }^{2}$ Ele tem que integrar o que o autor não diz, tem que romancear a sua personagem, fazendo da palavra um órgão vivo.

O texto romanesco, ao ser utilizado como espetacular, precisa ser visto como uma "partitura" a ser decomposta em pedaços pelo diretor e/ou adaptador, respeitando o macro-signo do texto na hora da concepção da montagem. A adaptação, vista por nós como releitura ou mesmo tradução, é o ponto de partida para que a encenação do romance seja concretizada. Geralmente esse trabalho - seja a traduçāo de um romance em espetáculo (como a realizada por Antônio Abujamra e o grupo Os Fodidos Privilegiados do romance O casamento, de Nelson Rodrigues, ou pelo grupo Rajatabla com o texto Ninguém escreve ao coronel, de Gabriel García Márquez) ou mesmo a adaptação de um texto dramático (montagem d'O beijo no asfalto pelo grupo Reviu a Volta e montagem d'El continente negro pelo grupo Mayombe) - tem que ser tratado com rigorosidade artística pela direção da peça, de acordo com as necessidades de seu grupo. Gershon Shaked, atento a essa nuança, nos coloca:

\footnotetext{
' Conceito utilizado por Marco de Marinis em oficina, de mesmo nome, ministrada no ECUM, maio de 1998.

${ }^{2}$ Informação extraída da oficina A dramaturgia do ator, ministrada por Marco de Marinis no ECUM, maio de 98.
} 
Una alternativa más elaborada que el director tiene a la mano es la de presentar una obra tradicional con vestimenta moderna, sin cambiar el texto en sí, trasponiendo los materiales sin cambiar sus normas básicas. Así, el diretor toma la obra como algo dado, pero trata de arrojar nueva luz sobre ella. ${ }^{3}$

Com essa colocação queremos dizer que o texto em si necessita ser lido no contexto de sua situação de enunciação, observando principalmente suas características intertextuais em relação à cultura na qual ele está inserido. Nesse sentido, temos que levar em consideração que a adaptação/tradução para teatro ${ }^{4}$ não deve ser considerada como uma simples decodificação lingüística, mas sim, antes de tudo, como uma decodificação semântica, estilística e, sobretudo, cultural. Com isso queremos enfatizar, ainda que possamos parecer repetitivos, que o texto é apenas um dos elementos da representação, porém dentro do contexto teatral e da tradução/adaptação é nele que está um grande número das dimensōes ideológicas, culturais e etnológicas que deverão ser colocadas no palco para que o mesmo possa parecer "visível" (suscetível de ser concretizado no cenário pelo atores) para o público. O que nos permite apropriarmos das palavras de Patrice Pavis quando ele conclui seu parecer sobre os problemas da tradução para cena:

(...) A esta inquietante circularidad se le viene a agregar el hecho de que la traducción para el teatro nunca está donde uno espera que esté: no está en las palavras, sino en el gesto; no está en la letra, sino en el espíritu de una cultura, inefable pero omnipresente. ${ }^{5}$

Outros pontos a serem evidenciados, dentro do contexto da obra romanesca, dramatúrgica e espetacular, são os papéis do leitor e do espectador. Os textos são processos de significação que só se materializam mediante à pratica da leitura. Portanto, podemos afirmar que o leitor cumpre um papel tão importante quanto o do autor (assim como o espectador o realiza dentro do trabalho espetacular) no universo literário, como nos evidencia Terry Eagleton:

(...) O leitor estabelece conexões implícitas, preenche lacunas, faz deduções e comprova suposições - e tudo isso significa o uso de um conhecimento tácito do mundo em geral e das convençōes literárias em particular. $O$ texto, em si, realmente não passa de uma série de "dicas" para o leitor, convites para que ele dê sentido a um trecho de linguagem. Na terminologia da teoria da recepção, o leitor "concretiza" a obra literária, que em si mesma não passa de uma cadeia de marcas negras organizadas numa página. Sem essa constante participação ativa do leitor, não haveria obra literária. ${ }^{6}$

O leitor, para ser bem sucedido, necessita estar sujeito a ser "transformado" pelo texto sempre, estando pronto para jogar e se arriscar a novas transformaçōes, refazendo sempre que necessário o seu horizonte de expectativas, construindo um outro texto coerente com o lido. Tudo no texto (suas lacunas, suas unidades formais, sua gramática, seus significados) é passível de interpretação e caberá ao leitor estar disposto a colocar suas impressões em xeque para decifrá-lo. Por isso que se há afirma-

\footnotetext{
${ }^{3}$ SCOLnicov \& Holland. La obra de teatro fuera de contexto. El traslado de obras de una cultura a outra, p. 22.

${ }^{4}$ Estou me referindo à tradução/adaptação teatral, entretanto os pontos abordados também devem ser considerados quando estivermos lidando com qualquer tipo de tradução literária.

${ }^{5}$ SCOLNICOV \& HOLlAND. La obra de teatro fuera de contexto. El traslado de obras de una cultura a outra, p.62.

${ }^{6}$ EAGLETON. Teoria da literatura: uma introdução, p.82.
} 
do que nenhuma leitura é inocente. Nós, enquanto leitores, somos e estamos situados histórica e socialmente, o que faz com que nossa maneira de ler e interpretar as obras literárias seja condicionada a esse fato, fazendo com que sejamos mais "tocados" por certos tipos de textos romanescos, dramáticos ou espetaculares. Como exemplos, podemos citar os textos de Nelson Rodrigues, que continuam "mexendo" com as pessoas que os lêem ou os assistem no palco, e também Rua da Amargura e Romeu e Julieta (do grupo Galpão), espetáculos que, ano após ano, são reencenados com êxito. Marco de Marinis, ao falar sobre o texto espetacular, nos diz:

Las diferentes disciplinas, semiológicas y otras, que se han ocupado en los últimos años de la textualidad (no sólo literaria), ya han aclarado de manera definitiva que todo texto siempre es incompleto, y exige a su destinario (lector, espectador) completarlo, actualizando sus potencialidades significativas y comunicativas. Ahora bien, esto es especialmente cierto en el caso del texto espectacular, dadas las peculiares y bien conocidas características de su producción y recepción (por una parte, sincreticidad multidimensionalidad, no persistencia en el tiempo e irrepetibilidad; por otra, simultaniedad entre producción y comunicación, copresencia física real de los emisores y los receptores).?

Dessa forma, a obra de teatro, como toda literatura, funciona como uma porta de entrada da cultura, pois nos permite participar de um "mundo" com o qual nem sempre estamos familiarizados. Uma das formas para podermos esclarecer essa nossa afirmação é a observação das obras que nos são apresentadas em outras línguas que não seja a materna. O espectador que nāo conhece o idioma falado vai ter que se apegar aos outros elementos semânticos para conseguir obter um entendimento global ou parcial das ações representadas. Isso faz com que o público "negocie" o sentido, dando mais atenção aos elementos não verbais, buscando na luz, no cenário, no tom de voz e corpo do ator, na música e em todos os signos presentes no espetáculo o seu entendimento. Podemos citar dois espetáculos onde o espectador se vê obrigado a fazer uso desses elementos: Kathakali Teatro Sagrado do Malabar - Teatro Mínimo Brasil/Índia e Silence - Teatro Mladinsko de Eslovénia, onde as únicas informaçōes que o espectador tem do espetáculo se dão através dos programas dos mesmos. Dessa forma, ele é obrigado a se entregar ao mundo de gestos e signos representados durante o espetáculo. Em Kathakali, aparecem no palco reis, rainhas, deuses e demônios ricamente maquiados e vestindo figurino tradicional onde são representados os mistérios da literatura indiana e, em Silence, como nos coloca Blaz Lukan: "Silence é um espetáculo que renuncia à palavra, mas não rejeita os efeitos teatrais. Embora o título dele, "Silêncio", nele quase não o encontramos." Os seis atores envolvidos na montagem conseguem nos passar com o corpo os sentimentos múltiplos que são evocados durante o espetáculo. Esses atores, em seis situações e cenários diferentes (uma densa teia de aranha, paisagens de pedras, construções de papéis, etc.), trabalham com as possibilidades que oferecem a voz e o corpo humanos, introduzindo no desenvolvimento do espetáculo diferentes movimentos acrobáticos e formas de dança que vão do balé clássico até a dança contemporânea.

Em relação ao direcionamento das artes cênicas em nossa cidade, é importante que destaquemos, por exemplo, a quantidade de grupos amadores e profissionais que

\footnotetext{
${ }^{7}$ MARINIs. Comprender el teatro - Lineamientos de una nueva teatrología, p.25. (os grifos são meus)

${ }^{8}$ Informação extraída do programa do espetáculo.
} 
vêm sendo criados em Belo Horizonte. Desses, alguns obtêm reconhecimento. Um dos fatores que possibilita esse aumento é o constante crescimento de profissionais que chegam ao mercado todo ano. Desses a grande maioria não consegue trabalho com facilidade ou se limita a fazer "pontas" em espetáculos de diretores já conhecidos em nosso meio, ${ }^{9}$ fazendo com que não haja uma mudança no tipo de trabalho realizado em nossa cidade. O tipo de espetáculo que ainda é garantia de teatro cheio em Belo Horizonte é o "pastelão" (Alô, alô Brasil) ou aquele que mexe com a libido (Blue Jeans, Foi bom meu bem). O espectador, quando vai ao teatro, de antemão, já tem um pré-conceito do que vai ver. Esse feeling nem sempre é positivo, pois rompe com a idéia do inesperado, do novo. Há que se preocupar com essa nuança se quisermos que haja uma evolução nas produçōes realizadas. Para esclarecer nosso ponto de vista, podemos citar o trabalho de grupo Galpão, que vem criando escola em nossa cidade. São vários os grupos que se inspiram no trabalho do Galpão na hora de conceber os seus espetáculos. O uso de elementos do circo, a presença do clown, a música criada e tocada pelo próprio grupo. Todas essas características, se não forem bem trabalhadas e diferenciadas no palco de acordo com objetivo de cada obra, fazem com que a montagem se torne apenas uma "cópia"; inclusive, é comum se ouvir o comentário: interessante, mas é Galpão, não? O próprio grupo, que já tem essa linha circense arraigada às suas montagens, se preocupa em aprimorá-la, diferenciando-a nos seus espetáculos de acordo com o propósito da peça e o texto em questão. Percebemos essa diferença claramente nas montagens Romeu e Julieta, Rua da Amargura, Um Molière imaginário e a última montagem do grupo, Partido. Todas apresentam os elementos já mencionados, entretanto em cada uma há uma preocupação de adequar esses ele. mentos ao propósito da montagem e do texto em questão. Shakespeare, Eduardo Garrido, Molière ou Ítalo Calvino adquirem uma "cara nova", como assinala Paulo Campos, redator do Estado de Minas, ao se referir à montagem Um Molière imaginário:

Se agora é Molière, é bom recordar que o Galpão antes já experimentou outros clássicos: fez um Nelson Rodrigues barroco em Álbum de família, traduziu em imagens de saltimbancos a comédia dell'arte italiana em Arlequim, servidor de tantos amores e encantou com a versão de Shakespeare, Romeu e Julieta. Neste novo, Molière não resistiu a estética circense do Galpão. ${ }^{10}$

Nessa linha podemos também citar o trabalho do Reviu a Volta, que também faz uso desses elementos, incluindo, inclusive, em seu espetáculo, uma cena inspirada pela montagem Rua da Amargura, mas sem se converter em um estereótipo do Galpão, visto que o grupo também surgiu com o objetivo de aliar teatro, música, dança e artes plásticas e passou a se dedicar ao teatro na rua, utilizando linguagens próprias, desenvolvidas a partir de elementos do circo, comédia dell'Art e do clown clássico, aliados à linguagem e signos do folclore e das culturas regionais.

José Celso Martinez nos fala:

Mexer com arte não é tabu, é totem. A intenção do teatro é atravessar a couraça das pessoas e se comunicar numa área fora das máscaras. Ou o teatro se comunica dessa

\footnotetext{
${ }^{9}$ Podemos citar Cida Falabela, Eid Ribeiro, Jota Dangelo, Marcelo Bones, Pedro Cava, entre outros.

${ }^{10}$ CAmpos. Estado de Minas, 21/06/97.
} 
forma com pessoas de qualquer idade, de qualquer sexo, de qualquer país, ou não é teatro. O objetivo do teatro na origem dele antes de ser roubado por um processo civilizatório é plugar as pessoas nessa região, é um lugar de reencontro do homem. ${ }^{11}$

Suas palavras sintetizam a nossa visão concernente ao papel do teatro em nossa sociedade. Aquele que funciona como um veículo no qual distintas problemáticas são discutidas ou colocadas em cena para a apreciação e discussão do espectador. Ainda que nem sempre esse objetivo seja alcançado, sabemos que toda peça que é levada ao público, busca, a priori, através das distintas linguagens envolvidas no espetáculo, o reconhecimento do público, o mesmo que é responsável pelo sucesso ou fracasso da peça. Keir Elam ${ }^{12}$ nos aponta que é com o espectador que a comunicação teatral inicia e termina. Sem a presença do espectador o teatro não vive, não vive o dramaturgo, não vive o diretor, não vive o ator, que tem de fazer com que sua forma de ence. nação seja vista pelo espectador como algo possível, ou seja, o ator deve estar total. mente presente na ação dramática ("corpo-mente"), só assim o espectador vai perceber o macro-signo.

\footnotetext{
${ }^{11}$ Martinez. Estado de Minas - Espetáculo - 26/03/98, p.7.

${ }^{12}$ ELAM. The semiotic of theatre and drama, p.97. (It is with the spectator, in brief, that theatrical communication begins and ends.)
} 


\section{RESUMEN}

El propósito de ese artículo es realizar un panorama de las artes escénicas en Belo Horizonte, en los últimos cinco años, partiendo del análisis de más de ochenta espectáculos asistidos en ese período y buscando tejer algunas consideraciones teóricas sobre el direcionamento del tea. tro en nuestra ciudad.

\section{PALABRAS-CLAVE}

encenificación, Belo Horizonte, grupos teatrales

\section{REFERÊNCIAS BIBLIOGRÁFICAS DE TEATRO}

Artaud, Antonin. O teatro e seu duplo. Trad. Teixeira Coelho, São Paulo: Martins Fontes, 1993.

Barba, Eugenio e Nicola Savarese. A arte secreta do ator: dicionário de Antropologia Teatral. Campinas: Unicamp, 1995.

BOAL, Augusto. Teatro do oprimido e outras poéticas políticas. Rio de Janeiro: Civilização brasileira, 1983.

Berrettini, Célia. O teatro ontem e hoje. São Paulo: Perspectiva, 1980.

Boleslavski, Richard. A arte do Ator. Trad. J. Guinsburg, São Paulo: Perspectiva, 1992.

Bornhem, Gerd A. A Cena Dividida. Porto Alegre: LP\&M, 1983.

BRIE, César. Por un teatro necesario. El Tonto del Pueblo. Bolivia: Plural Editores, 1995.

ElAm, Keir. The semiotic of theatre and drama. London. N. Y.: Methuen, 1980.

Grotowski, Jerzy. Em busca de um teatro pobre. Trad. Aldomar Conrado, 4 ed. Rio de Janeiro: Civilização Brasileira, 1992.

Guinsburg, J., Teixeira Coelho Neto, J., Chaves Cardoso, Reni. Semiologia do teatro. São Paulo: Perspectiva, 1988.

JoRnal Estado DE Minas. Espetáculo, 26 de março de 1988. (Entrevista com José Celso Martinez: Em festa com o papa das bacantes, realizada por Márcia Bechara.)

Leite Lopes, Ângela. Nelson Rodrigues trágico então moderno. Rio de Janeiro: Editora UFRJ/ Tempo Brasileiro, 1993.

MAGAldi, Sábato. Nelson Rodrigues: Dramaturgia e encenaçōes. 2a. edição, São Paulo: Perspectiva, 1992.

Magaldi, Sábato. O texto no Teatro. São Paulo: Perspectiva/Editora da Universidade de São Paulo, 1989.

MARINIS, Marcos. Comprender el teatro - lineamientos de una nueva teatrología. Buenos Aires: Editorial Calerna, 1997.

MARINIS, Marcos. Oficina - Dramaturgia do ator. ECUM. Belo Horizonte, maio de 98.

Pallottini, Renata. Dramaturgia: a construção do personagem. São Paulo: Ática, 1989.

RAVETTI, Graciela. Da fragmentação das Utopias: El continente negro, de Marco Antonio de La Parra. Revista de Estudos de Literatura, Vol. 4, Belo Horizonte: Centro de Estudos Literários da Faculdade de Letras da UFMG, 1996.

Rosenfeld, Anatol. Prismas do teatro. São Paulo: USP, 1993.

Rosenfeld, Anatol. Teatro moderno. 2 ed. São Paulo: Perspectiva, 1985.

Rosenfeld, Anatol. Texto/contexto. 4 ed. São Paulo: Perspectiva, 1985.

Rojo, Grínor. La obra dramática y la obra teatral (Anejo). Muerte y resurreción del teatro chileno. Madrid: Ediciones Michay, S.A., 1973-1983. 
Seibel, Beatriz. Historia del Circo. Buenos Aires: Ediciones del Sol, 1993.

Scolnicov, Hana, Hollant, Peter. (compiladores) La obra de teatro fuera de contexto. El traslado de obras de una cultura a outra. (Trad. de Martin Mur Ubosart) Madrid: Siglo Veintiuno editores, 1991.

Stanislavski, Constantin. Manual del actor. México: Ed. Diana, 1984.

STANISLAVSKI, Constantin. A construção da personagem. Introdução de Joshua Logan. Trad. Pontes de Paula Lima. 7 ed. Rio de Janeiro: Civilização Brasileira, 1994.

Ubersfeld, Anne. Semiótica teatral. Murcia: Cátedra, 1989.

\section{REFERÊNCIAS BIBLIOGRÁFICAS GERAIS}

EAgleton, Terry. Teoria da literatura: uma introdução. Trad. Waltensir Dutra. São Paulo: Martins Fontes, 1983.

Eco, Umberto. Lector in Fabula. São Paulo: Perspectiva, 1986.

Eco, Umberto. Tratado geral da semiótica. São Paulo: Perspectiva, 1986.

Zilberman, Regina. Estética da Recepção e História da Literatura. São Paulo: Ática, 1989. 